\title{
IMPACT OF GEOTECHNICAL FACTORS ON THE SAFETY OF LOW EMBANKMENT DAMS FROM THE PERSPECTIVE OF TECHNICAL AND SAFETY SUPERVISION
}

\author{
Andrej KASANA ${ }^{1 *}$, Marian MINÁRIK², Maroš NIKOLAJ'
}

\section{Abstract}

Our research deals with a broad spectrum of problems concerning the variability of geotechnical factors and their influence on the safety of the biggest group of dam constructions in Slovakia, i.e., low earthfill dams. Its specific aim is the observation of their risk factors by using our experience and knowledge gained while working in the sector of technical and safety supervision.

To achieve the aims of a research thesis, we analyzed 39 low earthfill dams. We performed observations and documented their conditions with the aim of clarifying the risk factors. After an analysis of the information materials that characterize dams and after a statistical analysis of the measurement results in situ, including measurements from technical and safety supervision databases, we performed an analysis by using mathematical modeling to evaluate the safety of the dam constructions. Out of the total number of 39 dam constructions, an analysis of the stability of the dam slopes was performed on 37 dams, and deformation problems were analyzed on 28 of the dams. Filtration problems were analyzed at 26 dams, and a complete evaluation of the intensity of filtration movements was performed on 19 of the constructions.

On the basis of a detailed analysis of the 39 dam constructions, we specified their problems and the concomitant consequences of the problems. Geotechnical risk factors and specific risks that determine the safety of water constructions were characterized.
Address

1 Vodohospodárska výstavba š.p., Karloveská 2, 842 04, Bratislava, Slovakia

2 Department of Geotechnics, Faculty of Civil Engineering, Slovak University of Technology in Bratislava, Radlinského 11 81005 Bratislava, Slovakia

Corresponding author: andrej.kasana@vvb.sk

\section{Key words}

- Dam safety,

- technical and safety supervision.

The analysis confirmed the importance of an engineer-geological and geotechnical checkup in the process of preparation and building (alternatively, during reconstructions and sanitation work) of such water constructions and also the importance of monitoring in the process of dam usage. Technical and safety checkups were also shown to be important when analyzing risk factors. The conclusions of the knowledge gained and the recommendations for the practice deal with recommendations to change the flow policy, develop a central project register, and develop documents and databases that are needed for analyses of the safety of low earthfill dam constructions in the Slovak Republic.

\section{INTRODUCTION}

Low embankment dams in the Slovak Republic make up the largest group of hydraulic engineering structures that are charged with regulating and retaining water and are subject to professional technical and safety supervision. These bodies are primarily protective levees and dams used at water regulation structures and reservoirs with a height of $15-20$ metres above their footings. They are considered to be low dams with a maximum height of 5 to 15 metres according to the International Committee for Large Dams (ICOLD). These structures represent from $80 \%$ to $98 \%$ of the total number of dams in the world.

The issue of geotechnical safety factors of low embankment dams has not received as much attention as those for more significant and taller dams or as much attention as the risk of dams overflowing and the lack of hydrological data.

A system of preventing accidents and failures in hydraulic engineering structures has been in place in the Slovak Republic for several 


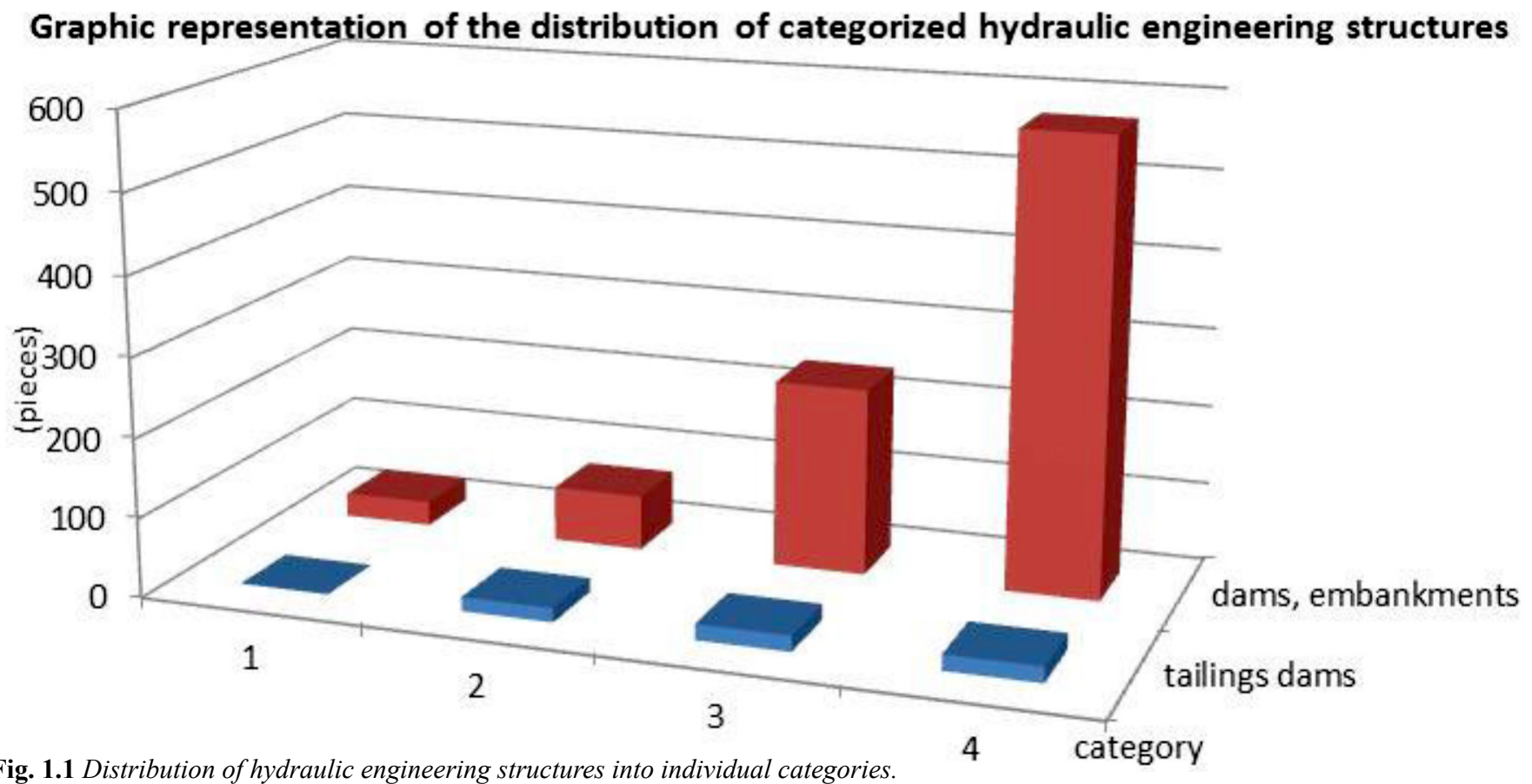

decades. This system involves professional technical and safety supervision based on existing legislative prerequisites that serve as the foundation of the actual activities conducted in practice, i.e., from project preparations to construction, the installation of measurement equipment, and the actual assessment of measurements. The system of evaluating the risks created by the individual types of hydraulic engineering structures, which is used to define the categories of hydraulic engineering structures that ultimately define the duties of builders and operators of hydraulic engineering structures, is particularly well-developed. All hydraulic engineering structures that regulate or retain water are assigned to one of four categories, whereby Category I contains structures that would result in the most catastrophic damage in the event of a failure and the release of the water retained by such structures. A list of hydraulic engineering structures is published at www.vvb.sk.

\section{Share of low embankment dams in} Category I
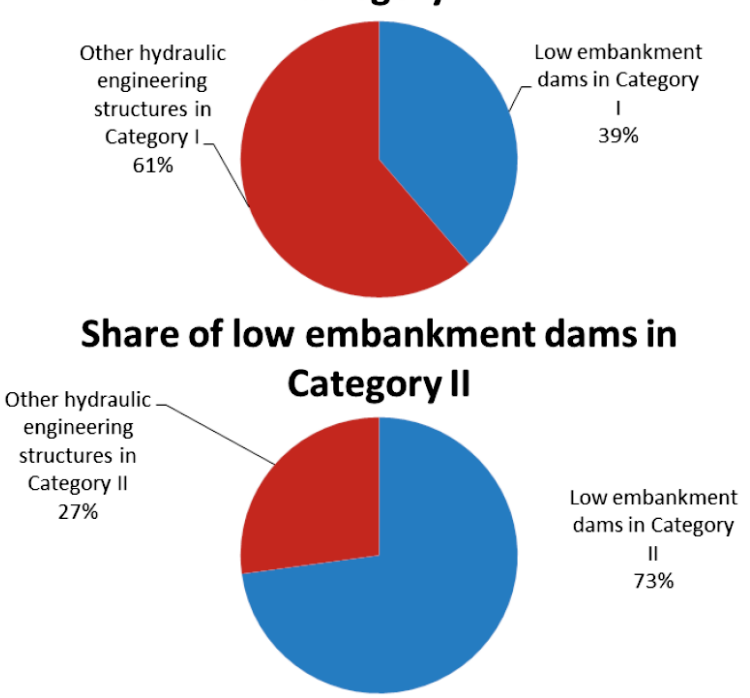

A total of 969 hydraulic engineering structures (including 59 tailings dams) were included on the list of hydraulic engineering structures categorized as of March 2014. A graphic representation of the distribution of categorized hydraulic engineering structures in the Slovak Republic, which are grouped into individual categories, is presented in Fig. 1.1.

Low embankment dams account for 690 of the 910 hydraulic engineering structures (969, including tailings dams) or $71.2 \%$ of all the categorized hydraulic engineering structures in terms of technical and safety supervision in the Slovak Republic. The state-owned SVP š.p. administers 431 of the 690 structures with low embankment dams. A graphic representation of the share of hydraulic engineering structures with low embankment dams in the total number of hydraulic engineering structures in individual categories is presented in Fig. 1.2.

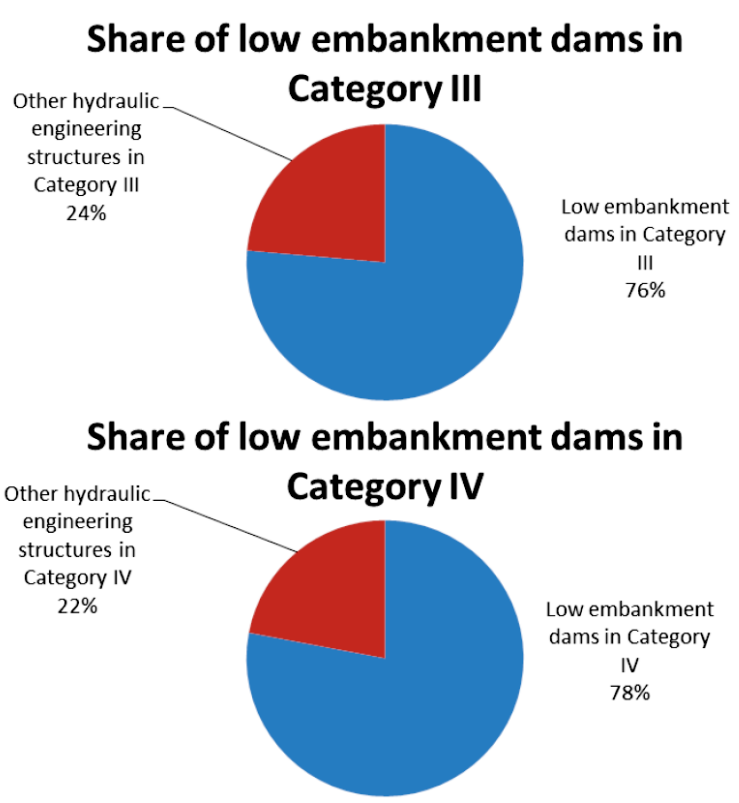

Fig. 1.2 Share of low embankment dams in Categories I, II, III and IV in Slovakia (as of March 2014, excluding tailings dams). 


\section{RESEARCH OBJECTIVES}

The research objective was to define the most common geotechnical problems and risk factors for low embankment dams using an analysis of selected hydraulic engineering structures with low embankment dam structures. In the process of describing the factors causing such problems on the hydraulic engineering structures evaluated, the individual risk factors are classified into common groups in practice and are assigned to such groups based on existing or potential risks.

Various methods are used to evaluate the safety of hydraulic engineering structures, and they are always based on the most common types of failures and accidents corresponding to the primary construction characteristics of the hydraulic engineering structures themselves and the methods used to identify risk factors inherent in the hydraulic engineering structures evaluated. Attention was focused within the research on the geotechnical safety factors of low embankment dams as one of the objectives of the work, which is to describe a method for evaluating safety and identifying risk factors.

The research's primary objective was to develop recommendations for practical applications on the basis of all the accumulated knowledge that leads to improved technical and safety supervision with respect to the timely identification of safety risks for low embankment dams.

\section{DAM SAFETY}

Dams and levees represent an important group of hydraulic engineering structures. Despite the fact that different types of loads are involved from an operational perspective (dams are loaded continuously, while levees are only subject to hydrodynamic stress for a short duration during heightened flood water levels and flows), specific parallels exist between these structures with respect to safety. The basis for evaluating the safety of low embankment dams and levees is knowledge of the primary causes of dam failures and accidents. Statistical data has documented that the fundamental causes of dam accidents are water overflowing the top of a structure, infiltration through the body and footing of a dam, and the incorrect incorporation of structures into the bodies of levees. The causes of accidents involving embankment dams can be divided into 3 basic groups:

- Accidents and catastrophes caused by hydrological factors,

- Accidents of a geotechnical nature: Infiltration, Slope slides, Excessive settling of the body and footing,

- Other unspecified causes.

\section{DEFINING THE CONDITION OF LOW EMBANKMENT DAMS IN THE SLOVAK REPUBLIC}

The research involved the selection of hydraulic engineering structures for which up-to-date safety evaluations, definitions of risk,

Tab. 3.1 Causes of dam failures in percentages (Lou, 1981). and the determination of the limit and critical values of phenomena monitored within the technical and safety supervision, were all lacking, with consideration given to the needs of the largest administrator of such hydraulic engineering structures (SVP s.p.) with the low embankment dam structures then selected from this subset. A total of 39 hydraulic engineering structures out of a total of 431 low embankment structures administered by SVP š.p. were analysed in terms of geotechnical safety factors (around $9.1 \%$ ), and an analysis of their condition was completed with the use of the mathematical modelling of deformations, infiltrations and slope stability. Dams from all the categories are represented in the group of 39 low embankment dams analysed with most of the structures classified as Categories II and III in terms of their technical and safety supervision in a manner corresponding to their share in the overall number of categorized structures with a sufficient range of measurement equipment required for a more comprehensive analysis. This also explains the lower number of Category IV hydraulic engineering structures in the analysis (Fig. 4.1), as measurement equipment is only installed on Category IV hydraulic engineering structures in rare cases and as the hydraulic engineering structure analysis without the results of a long-term analysis could only then be based on mathematical modelling, which cannot be verified against the measurement results.

Representation of low embankment dams in the individual categories of hydraulic engineering structures

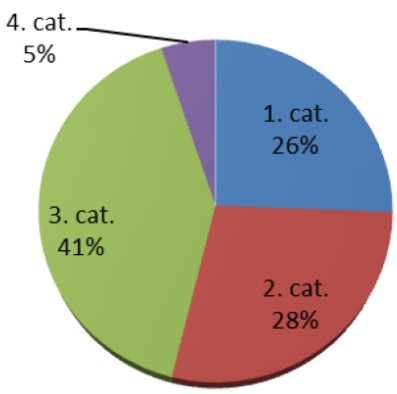

Distribution of the analysed structures by the administrator

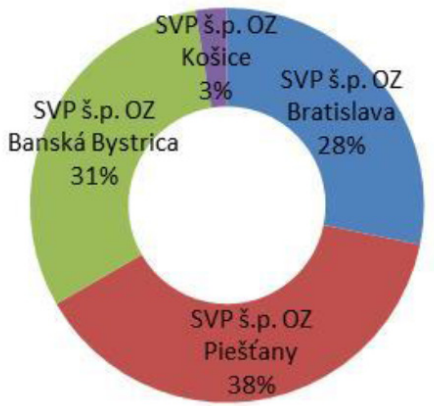

Fig. 4.1 Percentage representation of low embankment dams in the individual categories of hydraulic engineering structures in the analysis (left) and the distribution of the structures analysed by the administrator (right).

\begin{tabular}{|l|c|c|c|c|c|c|}
\hline Cause of failure & $\begin{array}{c}\text { Middlebrooks } \\
(1953)\end{array}$ & $\begin{array}{c}\text { Gruner } \\
(1967)\end{array}$ & $\begin{array}{c}\text { Takase } \\
(1967)\end{array}$ & $\begin{array}{c}\text { Babb - } \\
\text { Mermel } \\
(1968)\end{array}$ & $\begin{array}{c}\text { Biswas - } \\
\text { Chatterjee } \\
(1971)\end{array}$ & $\begin{array}{c}\text { USCOLD } \\
(1975)\end{array}$ \\
\hline Spillway or overtopping & 30 & 23 & 28 & $\mathbf{3 6}$ & 35 & 38 \\
Piping or seepage & $\mathbf{3 8}$ & $\mathbf{4 0}$ & $\mathbf{4 4}$ & 30 & 25 & $\mathbf{4 4}$ \\
Slides & 15 & 2 & 10 & 15 & 9 \\
Miscellaneous & 17 & 35 & 18 & 19 & $\mathbf{4 0}$ & 9 \\
\hline
\end{tabular}


Low embankment dams located in eastern Slovakia are left out of the analysis, given the increased travel and time demands for their inclusion, in particular with regard to the need to conduct a physical inspection of the hydraulic engineering structures analysed in addition to processing the available documentation and measurement results as well as the completion of mathematical modelling and an evaluation of the results in order to complete a comprehensive analysis of such structures.

One output generated by the research is an overview of the 39 hydraulic engineering structures with low embankment dams (dams and important levees) in the Slovak Republic. This overview provides the name of the hydraulic engineering structure as well as the maximum height of the dam, a descriptor stating whether the dam has a homogeneous or heterogeneous structure, and a descriptor of any analysis and mathematical modelling (if an analysis of the hydraulic engineering structure included the slope stability, or if the final elements modelling method was used for determining any deformations and stress, and if any groundwater and infiltration water flow problems were resolved using the final elements model comprehensively or only partially using an analysis of hydraulic iso-lines). The problems or potential problems identified and geotechnical risk factors were then assigned to such data.

\section{ANALYSIS OF GEOTECHNICAL RISK FACTORS FOR LOW EMBANKMENT DAMS}

A total of seven primary risk factors were identified within the 39 hydraulic engineering structures with low embankment dams analysed:

- Unsuitable material composition in the body or footing of the dam,

- Structural faults based on design faults as well as faults and failures to respect technological discipline during dam construction,

- Unreliability of the monitoring system for measuring the technical and safety supervision,

- Increased seismic risks at the dam site,

- Historical hydraulic engineering structure,

- Uncertainty regarding the material composition of the dam itself and its footings,

- Impact of the environment and operations.

An unsuitable material composition can also be considered a structural fault, but with respect to the relatively high frequency of the occurrence of this problem, it was deemed a separate risk factor within the research on these hydraulic engineering structures analysed. The most frequent group of problems identified in the hydraulic engineering structures analysed were structural faults based on design faults as well as faults and failures to respect technological discipline during

Tab. 5.1 Percentual representation of risk factors.

\begin{tabular}{|l|c|}
\hline \multicolumn{1}{|c|}{ Geotechnical risk factor } & \% occurrence \\
\hline Unsuitable material composition & 25.6 \\
\hline Structural faults & 59.0 \\
\hline Unreliable monitoring system & 30.8 \\
\hline Increased seismic risk & 7.7 \\
\hline Historical hydraulic engineering structure & 7.7 \\
\hline Uncertainty in material composition & 28.2 \\
\hline Impact of the environment and operations & 5.1 \\
\hline No risk factors recorded & 12.8 \\
\hline
\end{tabular}

the dam construction. An unreliable monitoring system decreases the efficiency of the technical and safety supervision, while also representing a major risk factor given the incorporation of the measurement equipment and the boreholes into the body and footing of the dam in particular, as there are many documented cases where such activities pose a threat to the safety of the hydraulic engineering structure itself.

The following table provides a percentual representation of the individual geotechnical risk factors for the hydraulic engineering structures analysed:

An overview of the risks posed by geotechnical risk factors was completed for the 39 hydraulic engineering structures analysed. The risks associated with filtration failures were merged together into a common group for purposes of comparison with the most common global risks of accidents and failures involving dams and levees and to express the actual risks associated with the geotechnical risk factors identified for the low embankment dams analysed.

The following risks were merged into the filtration failure category:

- Risk of infiltration and seepage,

- Risk of dam body materials floating into the gate tunnel,

- Risk of seepage and erosion,

- Risk of a failed drainage system,

Based on a number of risk factors:

- Unsuitable material composition,

- Structural faults,

- Environmental influences.

The following risks were merged into the slope instability category:

- Risk of threats to slope stability,

- Risk of local slides,

Based on a number of risk factors:

- Unsuitable material composition,

- Structural faults,

- Historical hydraulic engineering structure,

- Increased seismic risk.

The following risks were merged into the excessive settling category:

- Risk of increased dam body deformations,

- Risk of increased dam footing deformations,

- Risk of local deformations in the levee bodies,

Based on a number of risk factors:

- Unsuitable material composition,

- Structural faults,

- Historical hydraulic engineering structure.

The risk of insufficient technical and safety supervision is based on the following risk factors:

- Unreliable monitoring system,

- Uncertainty in material composition,

- Historical hydraulic engineering structure.

The following risks were merged into the other risks category:

- Threat to the stability of gates, weirs and other flow regulation equipment connected to a dam,

- Risk of wave abrasion on guide slopes,

Based on a number of risk factors:

- Unsuitable material composition,

- Structural faults.

The percentages of the risks identified are graphically presented in Fig. 6.1. 


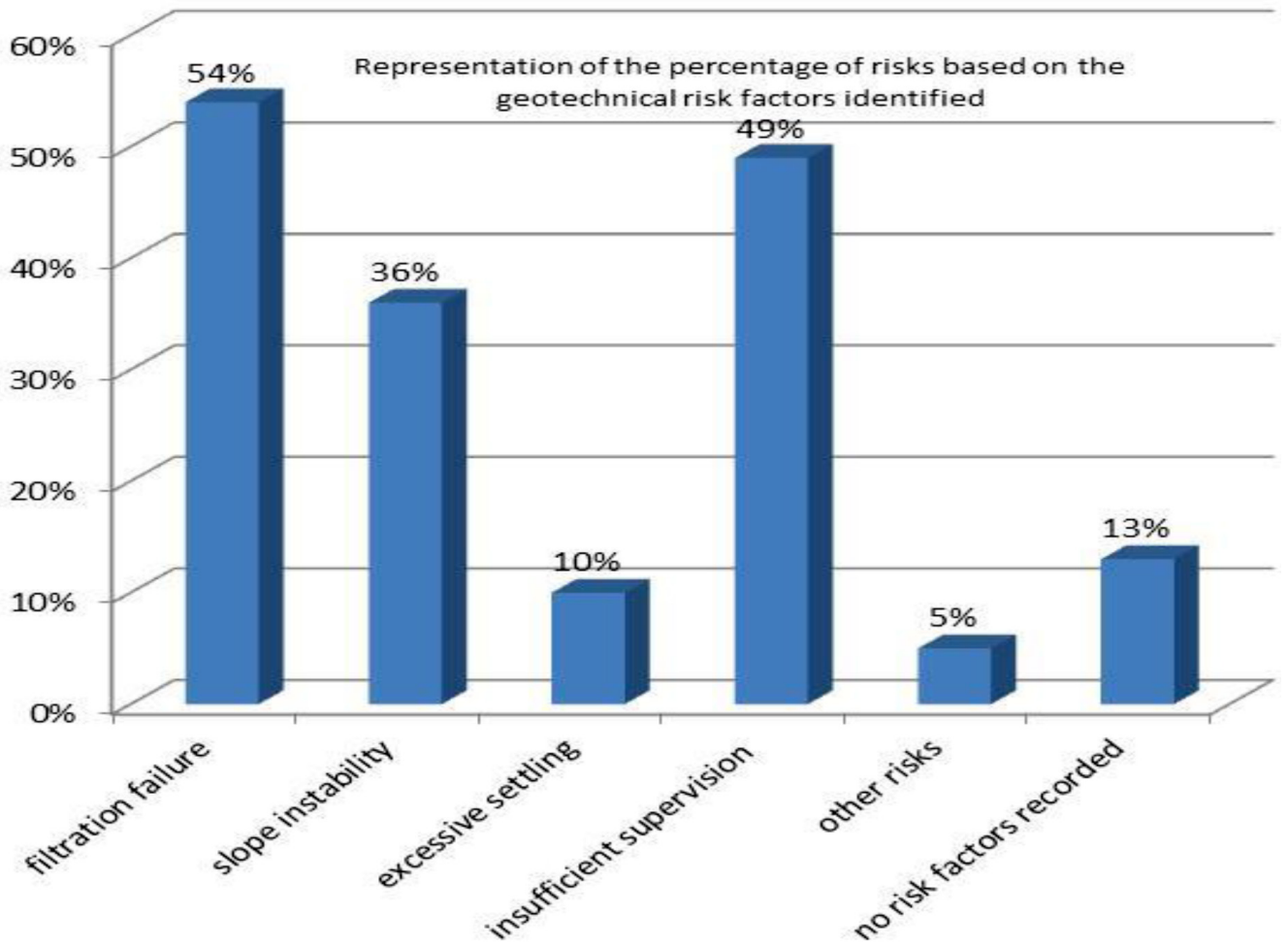

Fig. 6.1 Graphic representation of the percentage of risks based on the geotechnical risk factors identified.

It can be said that the occurrence of filtration failure risks is approximately the same in the Slovak Republic compared to other countries in terms of geotechnical risk factors when leaving out the risk of overflow and other failures caused by a lack of hydrological data, despite the fact that there is also a lack of foreign authors that deal exclusively with geotechnical safety factors for low embankment dams in works covering risk factors and the causes of such failures in hydraulic engineering structures.

In terms of an international comparison, the most interesting finding is the magnitude of the risk based on insufficient technical and safety supervision for low embankment dams in the Slovak Republic. This risk inherently involves the loss of the ability to make a timely identification of other risk factors and the loss of the related ability to complete timely measures to prevent accidents and failures. This risk in and of itself is unable to cause such failures or accidents but may significantly increase the magnitude of damage resulting from accidents and failures caused by other risks and their risk factors.

The risk of insufficient technical and safety supervision can be found in the category of "various" (or "other") in terms of the groupings provided by the authors of international statistics of failures and accidents, but domestically the risk of insufficient technical and safety supervision comprises more than $90 \%$ of such other risks, which is why it was presented as a separate risk.

\section{SUMMARY OF THE KNOWLEDGE GAINED AND RECOMMENDATIONS FOR PRACTICAL APPLICATION}

This research analysed the influence of geotechnical factors on the safety of low embankment dams in terms of technical and safety supervision. The impetus for selecting this topic was the fact that low embankment dams form a majority, i.e., $71.2 \%$ (or around $76 \%$ when excluding tailings dams) of all the registered and recorded hy- draulic engineering structures in the Slovak Republic.

Despite the fact that technical and safety supervision is a statutory duty and that its professionalism is guaranteed by the condition of professional competence to be fulfilled by the individuals authorized to conduct such supervision, the results of our research have shown that the most common risk factor after filtration failures is insufficient technical and safety supervision. In actual practice this means that data on the material composition of the dams and their footings are lacking for Category III and Category IV structures, while an excessive number of low embankment dams either lack a sufficient monitoring system or their existing monitoring systems may be considered unreliable.

The fact that nearly half (49\%) of the hydraulic engineering structures analysed were identified as lacking sufficient technical and safety supervision should serve as a warning signal to all professionally competent individuals who are primarily employees charged with supervising the hydraulic engineering structures analysed. It should also serve as a warning signal for administrators and owners of the hydraulic engineering structures analysed and for the Ministry of the Environment of the Slovak Republic, which is the central state authority for water administration, and which centrally assures the tasks of the department focused on the execution of professional technical and safety supervision.

A real shame is the fact that the results of previous analyses, laboratory analyses and special measurements have not been preserved due to the insufficient archiving of materials by the owners of these structures and that the original project documentation used to construct or later to rebuild and repair such structures has also been lost. The results of long-term measurements and observations from technical and safety supervision are also not frequently processed in the form of a database, and there is no guarantee that they will be archived.

An expansion of the existing list of hydraulic engineering structures, which should include a project documentation register, a register of documents, and a database for technical and safety supervision 
as well as a register of the results of analyses of categorized hydraulic engineering structures with the regular archiving of such documents on a mandatory basis (including electronic copies), would require that specific costs be expended by every hydraulic engineering structure owner and professionally competent individual (both in terms of human resources and space); however, similar to the Geofund, the benefits of such a step would far outweigh such costs and, in particular, deliver benefits in the form of the long-term safety and operational condition of structures with low embankment dams and all categories of hydraulic engineering structures.

\section{REFERENCES}

Bednárová, E. - Lukáč, M. - Lukáč, M. - Minárik, M. - Bakaljarová, M. - Lipták, B. - Miščík, M. - Panenka, P. - Stoličný, J. (2010) Dam construction in Slovakia. Originalities. Milestones. Attractions. Bratislava, Slovakia, Kuskus, ISBN: 978-80970428-0-6

Jandora, J. (2007) Catastrophic failure of the dam. Habilitation, Brno University of Technology, Faculty of Civil Engineering, Institute of Water Structures, Brno, Czech Republic.

Lou, W. C. (1981) Mathematical modeling of earth dam breaches. Dissertation, Colorado State University. Fort Collins, Colorado, USA
Ř́íha, J. (2010) Rivers protective dikes. Grada, Prague, Czech Republic.

Schnitter, N. J. (1994) A History of Dams, The Useful Pyramids. A. A. Balkema: Rotterdam, Netherlands.

Šejnoha, M. (2009) GEO FEM - Theoretical manual. FINE Ltd., Prague, Czech Republic. 